\title{
Review \\ High-Intensity Conditioning for Combat Athletes: Practical Recommendations
}

\author{
Alan Ruddock ${ }^{1, *(\mathbb{D})}$, Lachlan James ${ }^{2} \mathbb{D}$, Duncan French ${ }^{3}\left(\mathbb{D}\right.$, David Rogerson ${ }^{1} \mathbb{D}$, Matthew Driller $^{2}(\mathbb{D})$ and \\ David Hembrough 1 \\ 1 Sport and Physical Activity Research Centre, Sheffield Hallam University, Sheffield S10 2BP, UK; \\ d.rogerson@shu.ac.uk (D.R.); d.hembrough@shu.ac.uk (D.H.) \\ 2 Sport and Exercise Science, School of Human Services, Allied Health and Sport, La Trobe University, \\ Melbourne, VIC 3086, Australia; L.James@latrobe.edu.au (L.J.); M.Driller@latrobe.edu.au (M.D.) \\ 3 UFC Performance Institute, Las Vegas, NV 89118, USA; dfrench@ufc.com \\ * Correspondence: a.ruddock@shu.ac.uk; Tel.: +44-1142254439
}

check for updates

Citation: Ruddock, A.; James, L.; French, D.; Rogerson, D.; Driller, M.; Hembrough, D. High-Intensity Conditioning for Combat Athletes: Practical Recommendations. Appl. Sci. 2021, 11, 10658. https://doi.org/ 10.3390/app112210658

Academic Editor: Alessandro de Sire

Received: 6 October 2021

Accepted: 21 October 2021

Published: 12 November 2021

Publisher's Note: MDPI stays neutral with regard to jurisdictional claims in published maps and institutional affiliations.

Copyright: (c) 2021 by the authors. Licensee MDPI, Basel, Switzerland. This article is an open access article distributed under the terms and conditions of the Creative Commons Attribution (CC BY) license (https:// creativecommons.org/licenses/by/ $4.0 /)$.

\begin{abstract}
Combat sports have been practiced for millennia and today are predominant sports at the Olympic games, with international organizations that host world, continental and national championships at amateur standard. There are also an increasing number of professional combat sports with global audiences. The growing popularity of professional combat sports and their importance at the Olympic games have led to an increase in scientific studies that characterize the physical, physiological, nutritional, biomechanical and training strategies of combat sports athletes. These studies characterize combat sports as high-intensity sports which require training strategies to develop the high-intensity capabilities of athletes. Therefore, the aim of this article is to (i) summarize the physiological demands of combat sports; (ii) present the primary considerations required to program high-intensity conditioning for athletes; (iii) define and present key highintensity conditioning methods; and (iv) provide guidance for scientists and coaches to help prepare athletes under common but differing circumstances.
\end{abstract}

Keywords: physical fitness; boxing; MMA; physiology; strength and conditioning; performance; exercise

\section{Introduction}

Human civilizations and cultures have engaged in combative activities associated with warfare for millennia. Today, modern versions of these controlled activities, collectively termed "combat sports", are predominant events at the Olympic Games, where boxing (39 medals), judo (43 medals), taekwondo (24 medals), freestyle wrestling (36 medals), and Greco-Roman wrestling (18 medals) and Karate (Kumite $=18$ medals), comprise approximately $16 \%$ of the total medals awarded. In professional and amateur combat sports, participants can either strike an opponent using their fists, elbows, knees, head or feet (i.e., striking sports); wrestle, throw, or pin an opponent on the ground (i.e., wrestling sports); or grapple with an opponent in an effort to manipulate their body in order to perform joint locks and chokes (i.e., grappling sports) [1,2]. In sanctioned and organized combat sports, contests are won by scoring a knockout, submission, technical knockout (referee or corner stopping the contest), or judges awarding points for superior technical ability and contest control [1,2].

The search term "combat sports" in the PubMed database (June 2021) returns a 3-fold increase in publications in the last decade compared to the previous 6 decades, indicating an exponential growth in research and an improvement in knowledge and understanding regarding the preparation of combat athletes for competition. In parallel, the evidence base for high-intensity conditioning methods has also improved [3-8] but at present, there has been limited exploration into the practical application of high-intensity conditioning strategies for combat sport athletes. This is somewhat surprising considering the potential for 
high-intensity conditioning to develop the aerobic, anaerobic and neuromuscular qualities that underpin combat sport performance. Indeed, recent literature reviews have highlighted the beneficial role of high-intensity conditioning in combat athletes and concluded that high-intensity conditioning positively influences aerobic and anaerobic capabilities that underpin performance $[9,10]$. Therefore, the aim of this manuscript is to (i) summarize the physiological demands of combat sports in general; (ii) present the primary considerations required to program high-intensity conditioning for combat sport athletes; (iii) define and present key high-intensity conditioning methods and (iv) provide guidance for scientists and coaches to help prepare athletes under common but differing circumstances.

\section{General Physiological Demands of Combat Sports}

Typical values reported in the scientific literature for aerobic capacity are presented in Table 1 . These values are weight class independent; and as such, are reported as typical upper limits for each fighting style. In general, the greater the potential duration of a contest and the total number of 'attacks', the greater the requirement for well-developed aerobic capacity. Combat sports that are shorter in duration and are comprised primarily of grappling or wrestling tend to require relatively lower aerobic capacity (Table 1). Nevertheless, a greater aerobic capacity has been related to a higher standard of performance in boxing, wrestling, and judo; however, some studies indicate no difference between standards [1]. These discrepancies might be due to the differing methodology implemented by studies and the range of continuous exercise tests performed in sport-specific settings. Interestingly, performance in a sport-specific intermittent test, but not aerobic capacity, was able to distinguish between national and regional karate competitors [11]. This is somewhat expected, because although combat sport athletes require well-adapted aerobic energy systems, these sports also place considerable demands on anaerobic and neuromuscular systems during competition. Indeed, approximately $77 \%$ of MMA contests are won by highintensity actions lasting between 8 and $12 \mathrm{~s}$, requiring substantial activation of anaerobic and neuromuscular systems; this duration is longer in higher-standard competitions [12]. In 2014, contest termination was associated with a mean of $20 \mathrm{~s}$ of standing (principally striking)-based high-intensity combat and $45 \mathrm{~s}$ of ground-based high-intensity combat in UFC bouts scheduled for 3 rounds [13] and victories were associated with approximately $60 \mathrm{~s}$ of prior high-intensity activity in 5-round bouts [14]. Blood lactate concentrations exceeding $10 \mathrm{mmol} \cdot \mathrm{L}^{-1}$ have been consistently reported in boxers and MMA athletes $[15,16]$ during simulated competition, underlining the substantial activation of anaerobic energy pathways in these combat sports.

Given these physiological demands, researchers have concluded that the majority of combat sports can be characterized as intermittent high-intensity impact sports (Table 1). However, the association between 'high-intensity' and 'anaerobic' characteristics and the subsequent notion that anaerobic capabilities are of primary importance in combat sports might be misunderstood in the context of actual performance, as true anaerobic performance (i.e., single maximum efforts lasting up to $20 \mathrm{~s}$ as reported from laboratorybased assessments) is rarely replicated. It is more likely that sustained high-force activities ( 8 to $12 \mathrm{~s}$ ) leading to contest termination occur later in bouts after significant and prolonged anaerobic and neuromuscular demand. For example, a technical knockout in boxing might occur in the 10th round after $30 \mathrm{~min}$ of intense competition. In these instances, the success of a high-intensity strategy is dependent on a well-developed aerobic rather than anaerobic energy system, with a key supporting role played by the neuromuscular system. Indeed, the diminishing contribution of the anaerobic glycolytic pathway to repeated high-force activities has been demonstrated even in $10 \times 6 \mathrm{~s}$ sprints with $30 \mathrm{~s}$ recovery and a relative increase in aerobic energy system contribution to $30 \mathrm{~s}$ maximal sprints when these sprints were performed three times with a rest period of $4 \mathrm{~min}[17,18]$. Performance in these activities was reliant on substantial activation of the aerobic energy system to perform at high intensity, akin to a key or final tactical component of performance in combat sports. 
Table 1. General characterization of major disciplines in combat sports. Estimated maximum aerobic capacity represents reported upper-limit independent of weight classification.

\begin{tabular}{|c|c|c|c|c|c|c|c|}
\hline Sport & $\begin{array}{l}\text { Duration of } \\
\text { Round } \\
\text { (min) }\end{array}$ & $\begin{array}{c}\text { Recovery } \\
\text { between } \\
\text { Rounds (min) }\end{array}$ & $\begin{array}{l}\text { Maximum } \\
\text { Number of } \\
\text { Rounds }\end{array}$ & $\begin{array}{l}\text { Total } \\
\text { Duration } \\
\text { (min) }\end{array}$ & $\begin{array}{c}\text { High-Intensity Activity } \\
\text { Profile (Activity to Rest } \\
\text { Ratio) }\end{array}$ & $\begin{array}{c}\text { Estimated Maximum } \\
\text { Aerobic Capacity } \\
\left(\mathrm{ml} \cdot \mathrm{kg} \cdot \mathrm{min}^{-1}\right)\end{array}$ & Sport Characterization \\
\hline $\begin{array}{l}\text { Boxing } \\
{[19]}\end{array}$ & 3 & 1 & 12 & 47 & $1: 1$ to $1: 3$ & 65 & $\begin{array}{c}\text { High-intensity impact } \\
\text { sport }\end{array}$ \\
\hline $\begin{array}{l}\text { Kickboxing } \\
{[20]}\end{array}$ & 2 & 1 & 12 & 35 & $1: 2$ to $1: 5$ & 60 & $\begin{array}{c}\text { Short-duration, } \\
\text { high-intensity bursts of } \\
\text { activity }\end{array}$ \\
\hline MMA [1] & 5 & 1 & 5 & 29 & $1: 4$ to $1: 5$ & 63 & $\begin{array}{c}\text { High-intensity impact } \\
\text { sport }\end{array}$ \\
\hline Judo [21] & 5 & NA & NA & 5 & $2: 1$ to $3: 1$ & 50 & $\begin{array}{l}\text { High-intensity impact } \\
\text { sport }\end{array}$ \\
\hline $\begin{array}{l}\text { Wrestling } \\
\text { [22] }\end{array}$ & 3 & 0.5 & 2 & 6.5 & Data not available & 55 & $\begin{array}{c}\text { Intermittent } \\
\text { high-intensity activity }\end{array}$ \\
\hline $\begin{array}{l}\text { Taekwondo } \\
\text { [23] }\end{array}$ & 2 & 1 & 3 & 8 & $1: 6$ to $1: 4$ & 63 & $\begin{array}{l}\text { Short bouts of rapid } \\
\text { high-intensity activity }\end{array}$ \\
\hline
\end{tabular}

A successful tactical strategy and the determination of contest pace are dependent upon critical intensity, demarcated as the upper limit of the severe-intensity domain just above the second lactate turnpoint with a time limit of approximately $30 \mathrm{~min}$ [24]. Exercise above this intensity domain is characterized by a $\dot{\mathrm{VO}}_{2}$ slow component that rises to $\dot{\mathrm{VO}}_{2 \text { peak }}$ with a significantly shorter exercise duration than below critical intensity. The role of welladapted critical intensity and aerobic capacity is also important in intermittent activity [25] Repeated high-force actions performed at a greater intensity than critical intensity require adequate 'recovery', supported by aerobic capabilities. It is also worth noting that an athlete with a well-developed aerobic energy system will be able to reserve the utilization of energy above critical intensity $\left(\mathrm{W}^{\prime}\right)$ until strategically necessary. Moreover, where two athletes are matched for critical intensity, the athlete with a greater aerobic capacity is less likely to develop a $\mathrm{V}_{2}$ slow component that precedes fatigue [26].

Striking-predominant combat sports typically have larger aerobic capacities compared to grappling sport athletes (Table 1), and it appears as though the ability to repeat intermittent high-intensity activities differentiates performance standards to some extent. Indeed, it has been demonstrated that short periods of high-intensity activity are critical to winning performances; however, these activities, although anaerobic when viewed in isolation, are heavily supported by aerobic energy systems when considering previous high-intensity activities within a bout. This evidence suggests that combat athletes should develop aerobic capacity in a manner that also trains the ability to perform at high intensities.

\section{Factors Influencing High-Intensity Conditioning}

\subsection{Competition Schedule}

Professional combat athletes do not have seasonal fixtures unlike many other sports; instead, the competitive calendar is dictated by governing bodies, media corporations, and promotional companies and managers. As a result, a training camp (commencement of 'competition phase') length can be short (2-6 weeks) or long (up to 4 months) depending on the standard of the athlete and their international ranking. Amateur combat athletes, however, do have a competitive calendar, with competitions, tournaments and championships occurring at similar times each year, which in most circumstances gives a formal structure to the training process. This allows for the programming of clearly defined 'peaking' for competition at predetermined time points in the competitive calendar. In both circumstances (i.e., short-notice fight camps or traditional fight camps), the length of the fight camp places constraints on the athlete because desired physiological adaptations have defined time-frames according to our understanding of basic science. Furthermore, professional combat athletes, and in particular Mixed Martial Artists, have time-constraints imposed within a camp length due to the multitude of training modalities they must ad- 
dress in order to prepare for all facets of the sport. Indeed, managing stylistic training (e.g., wrestling, striking, jiujitsu) with holistic sport-specific training (e.g., chain-wrestling or transitional striking into take-down), and in particular sparring, which is often emphasized towards the end of a fight camp, can present a significant training management challenge. For the amateur athlete, considerations must also be given to employment, study, family, travel and financial circumstances, which all place considerable demands on time required to comply with high-intensity conditioning programs. Failure to respect these demands can lead to maladaptation, non-functional overreaching and possibly overtraining [27,28].

\subsection{Weight Classification and Making Weight}

Most combat sports have competition structures based on weight classes, with the respective weight classes established to bring parity to competition by matching opponents together who are of similar size and stature. Athletes in combat sports, therefore, need to "make weight" before competition $[29,30]$. Weight-making methods adopted by athletes can occur over many weeks or months (i.e., chronic weight loss), usually inducing a negative energy balance for the purpose of reducing total body fat content, or more acutely over several days through the targeted manipulation of total body water [31], muscle glycogen [29], and dietary fiber [32]. In professional combat sports, athletes will often have completed the majority of their training 7 to 10 days before having to officially weigh in, meaning acute strategies have little impact on the training process. A major risk to both the quality and volume of high-intensity training that can be achieved is therefore often the impact of a negative energy balance induced during a longitudinal weight-decent phase in which caloric restriction can detrimentally impact training characteristics. An athlete who has under-fueled for a high-intensity conditioning session risks potential underperformance, psychological impacts of frustration caused by poor performance, injury, illness and a missed opportunity for quality training. Fueling to specifically optimize performance in high-intensity sessions is therefore crucial to the training process. Amateur athletes may undertake less aggressive weight-making strategies with the majority of weight-loss occurring during the week of the fight, or even the hours before, making training management important, especially in the context of seasonal periodization, as either a decrease in energy intake and or increased energy expenditure can influence training consistency and adaptation.

\subsection{Training History}

Choosing an approach to conditioning training, or energy system development as it is often referred to, should be dependent on an athlete's training history, and considerable attention must be placed on previous, current or potential injuries, movement and mobility function and or dysfunction, current body weight and composition. Common injury sites for combat sports include the head and face in boxing, knees in wrestling, thigh in taekwondo and lower back in judo [33], and as a result of these contraindications, decisions on adapted forms of training have to be made by the coaching team (e.g., simulated altitude, anti-gravity, heat- or water-based training). Another consideration is phenotypical dominances, dictated by genetics and previous training history. For example, if an athlete has a well-established career spanning 8 years as a professional with a substantial history of low-intensity cardiovascular training using 10 to $16 \mathrm{~km}$ of road running, training decisions regarding the suitability of high-intensity conditioning has to be taken into account. In this instance, the athlete might be more responsive to longer high-intensity interval training than shorter sprint interval training that requires different loading parameters or more challenging techniques. Throughout all phases of a training plan, consideration must be given to the need for an athlete to either reduce their physiological limitations or maximize their physiological strengths.

\section{Periodization of Training}

Periodization is the systematic manipulation of training variables to meet objectives at predetermined time points [34]. As such, a central tenant to periodization is an under- 
standing in advance of when competition is scheduled. This makes training-plan design challenging in combat sports as competition dates are often erratic and may only be confirmed a few weeks in advance in some cases. In addition, the frequency of competition generally differs between competition grades. For example, at the elite level, a fighter may compete in two to three bouts per year, whereas amateur and semi-professional fighters generally compete more frequently. Arguably the most challenging factor in designing a training plan is the need to develop a broad series of metabolic and neuromuscular qualities while also managing the stress of high-impact collisions. Because the endurance and strength attributes needed in combat sports (generally characterized by high overall training demand) are known to conflict during their simultaneous development [35], the periodization process must be carefully designed to minimize potential interference effects. The management of training variables must therefore consider: (i) the nature of the stimulus induced from sports-specific technical and tactical training; (ii) the shorter- and longer-term objectives of high-intensity interval training (HIIT) training when competition dates are unknown; (iii) the need to simultaneously develop multiple physical and physiological qualities, including strength, power, speed, and endurance. Traditional periodization for sports with a seasonal structure broadly divide training into preparation (i.e., pre-season), competition (i.e., in-season) and transition (i.e., off-season) phases. The preparation phase can consist of both general preparation and special preparation subphases. Similarly, pre-competition and competition subphases can form the overall competition phase.

Traditionally, fighters undertake targeted and structured training for approximately 1 to 3 months immediately prior to the event if notice of the fight allows. This has been termed 'fight camp' and can be treated as a 'competition phase'. However, during the remaining time (i.e., off camp), athletes still have an opportunity to engage in clearly structured training approaches that target 'general' and 'specific' adaptations. This framework should allow fighters to capitalize on the absence of competition and establish a foundation of well-developed physical qualities. It must also be flexible enough such that it enables fighters to transition swiftly into the later stages of the competition phase should a bout be taken on short notice.

\section{Periodization of High-Intensity Conditioning}

\subsection{General Preparation}

During the off-camp phase, the sports-specific contribution to the overall training demand will be lower than fight camp, as athletes and coaches prioritize technical development and skill rehearsal. This training will generally be characterized by technical drilling, which is often performed at lower intensities in an effort to maximize skill transfer and technically accurate skill execution (e.g., 'rolling' in Table 2).

The sports-specific training structure should involve longer work to rest intervals and a lower relative intensity (RPE 3-4 on CR10 scale [36]), resulting in predominant activation of aerobic energy systems with some contribution from anaerobic pathways with a low neuromuscular demand. However, maintenance doses of short higher-intensity efforts may be included to maintain previously established anaerobic qualities.

\subsection{Special Preparation}

During the special preparation subphase, there will be a shift from developing general metabolic functions with generic modalities to an increased amount of sports-specific training that reflects the bioenergetic requirements of competition. The inherent collisions that are present in the increased amount of sports-specific conditioning will expose the athlete to a greater neuromuscular demand than during the general preparation subphase. The contents of sports-specific high-intensity conditioning will contain a greater volume of sparring than that at the previous phase, albeit less than in early fight camp. The intervals can span 1 to 5 min of activity depending on the structure of the drill and the modality employed. 
Table 2. Estimated physical demands of different types of training for a typical MMA athlete. $+=$ low demand; $++=$ moderate demand; $+++=$ high demand.

\begin{tabular}{|c|c|c|c|c|c|c|}
\hline & Modality & Structure & Aerobic & Anaerobic & Neuromuscular & Technical \\
\hline \multirow{8}{*}{ Sport specific } & \multirow{3}{*}{$\mathrm{BJJ} /$ wrestling } & Drilling & ++ & + & + & +++ \\
\hline & & Open rolling & +++ & + & + & ++ \\
\hline & & Scenario rolling (i.e., shark tank) & +++ & ++ & ++ & + \\
\hline & \multirow{3}{*}{ Striking } & Technique & + & + & ++ & +++ \\
\hline & & Sparring & ++ & +++ & +++ & + \\
\hline & & Drilling & ++ & +++ & +++ & ++ \\
\hline & \multirow{2}{*}{ Combined (MMA) } & Technique & + & ++ & + & +++ \\
\hline & & Sparring & ++ & +++ & +++ & ++ \\
\hline \multirow{3}{*}{ Generic } & Cycling, rowing, other non-ballistic activities & & \multirow{3}{*}{\multicolumn{2}{|c|}{ Dependent on structure }} & + & - \\
\hline & Running & Modifiable & & & ++ & - \\
\hline & Resistance circuit & & & & ++ & + \\
\hline
\end{tabular}


In many cases, the next event may not be known which makes it difficult to determine the duration of the preparation subphases. To account for this, there must be flexibility in planning with the phase length long enough to enable meaningful adaptations but brief enough to enable agile manipulation should a bout be scheduled at short notice. A period of between approximately three to six weeks for each of the two preparation phases is a suitable option in many cases. A fighter can then cycle between the general and special preparation subphases until an event is confirmed. A key feature of this process is to increase the overall volume of each cycle to facilitate progressive overload thereby building greater fitness.

\subsection{Early Fight Camp}

Once the competition date is secured, the athlete can plan on moving into the competition phase, which consists of the early and later fight camp (equivalent to pre-competition and in-competition subphases in other sports). During early fight camp, the athlete will be exposed to a further increase in sports-specific high-intensity training, yet still less than found in late fight camp. During this subphase, the increased sports-specific training will generally come by way of increased striking and grappling drilling, sparring and technical work, and sport-specific conditioning (e.g., shark tanks). It is worth noting that high-intensity grappling will elicit a combined aerobic and anaerobic stimulus and can be structured with or without a neuromuscular emphasis. The distribution between striking and grappling sparring will be dictated by the fight strategy, which in turn is informed by the opponent's and fighter's strengths and weaknesses.

\subsection{Late Fight Camp}

The final block of fight camp (i.e., competition phase) differs by the greater volume of sports-specific training. The athlete will undertake more sparring and drilling that combine elements that replicate competition. This creates a combined aerobic-anaerobic stimulus from sports-specific training. The increase that takes place in the second block of the fight camp phase may often come from an increased number of rounds during a training activity. Additionally, characteristic of late fight camp is a greater focus on within-bout strategy and tactics. To taper, a reduction in overall training volume by approximately $40-60 \%$ over the final 8-12 days before competition is required to adequately dissipate the accumulated fatigue from training whilst maintaining a degree of intensity [37].

\subsection{Transition}

Following a competitive bout, athletes should undertake a period in which they allow for recovery from the rigors of competition, metabolic reset after restrictive weight-making strategies, and to allow for physical and mental reset after many weeks of challenging fight camp activities. This period of recovery and regeneration is often referred to as the transition phase. The duration of this can be largely dictated by the characteristics of a bout. For example, a fighter following a 5 round bout where considerable damage was sustained will require longer than a fighter who secured a swift victory in the first minute of the fight.

\section{Physiological Targets of High-Intensity Conditioning}

A fundamental prerequisite for successful high-intensity performance is a large aerobic capacity [38-40]. The principle contributing factors to aerobic capability can be broadly categorized into (i) oxygen delivery (cardiac output), (ii) oxygen extraction (muscle capillarization) and (iii) oxygen utilization mechanisms (mitochondrial content). As such, there are several targets of adaptation that underpin the development of aerobic capability. Cardiac output, and the delivery of oxygen to exercising musculature and the brain, is a limiting factor to maximum oxygen uptake [41]. Failure in the ability to pump blood to muscles limits aerobic capability and cardiac output is demonstrated to be largest in athletes with greater $\dot{\mathrm{VO}}_{2 \max }$ [41]. Athletes with larger aerobic capacities also possess a greater number of mitochondria as well as better function and capability to utilize oxidative 
enzymes [42]. Such physiological adaptations enable athletes to implement high-intensity strategies within their sport-specific technical training and subsequently performance plan in competition.

\subsection{Defining Training Type}

Precise definitions of high-intensity conditioning strategies have yet to be agreed. However, there is some acknowledgement that training types can be classified into the following categories: sprint interval training (SIT), HIIT, speed endurance training (SET) and muscle buffer training (BUFF) $[3,5-8,43]$.

Whereby:

- $\quad$ SIT: <30 s maximal exertion RPE 10/10—example 30 s maximum sprints [44].

- SET: from 30 to $60 \mathrm{~s}$ prescribed as ISO RPE 9/10-example $30 \mathrm{~s} \times 8$ with 3 min recovery [45].

- BUFF: intensities that elicit blood lactate concentrations between 8 and $12 \mathrm{mmol} / \mathrm{L}$ ISO-RPE of $8 / 10$ - example $6 \times 2$ min with 3 min recovery [8].

- HIIT: intervals from 2 to 20 min prescribed as an ISO-RPE of 9/10, 90\% maximum heart rate, or $90-95 \% \dot{\mathrm{VO}}_{2 \max }$-example $4 \times 8$ min with 2 min recovery between intervals [46].

Physiological targets for high-intensity conditioning reside on a continuum, rather than in discrete areas and a target is never exclusive to a single physiological adaptation. Figure 1 provides examples of the typical high-intensity conditioning sessions and position on the high-intensity continuum. It is generally considered that peripheral targets include the neuromuscular system and myocytes and central targets include the cardiovascular system $[5,6]$.

\section{CENTRAL}

\section{PERIPHERAL}

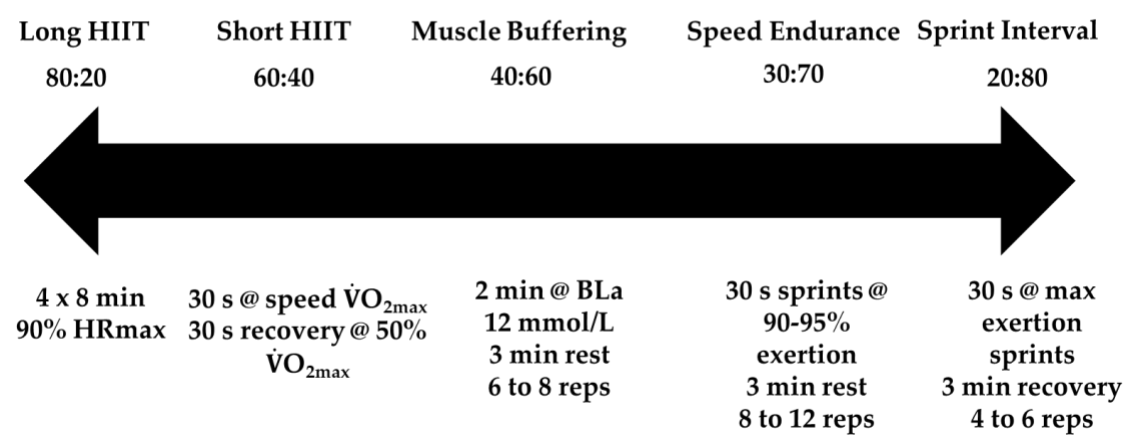

Figure 1. High-intensity conditioning continuum. Hypothetical demands of different types of conditioning method on central and peripheral factors to illustrate that each has type of training has dominant but not exclusive physiological target.

\subsection{Sprint Interval Training}

The general preparation phase provides the opportunity for coaches to program sprint interval training safely without conflicting demands from other aspects of training. Sprint interval training is typically performed on a cycle ergometer, non-motorized treadmill or outside on either a running track, grassy field or a hill with an incline of approximately $3-5 \%$. Other modalities such as versa climbers, ski ergometers, and rowing machines can also be utilized. The effectiveness of sprint interval training to improve high-intensity and endurance capability is well documented in sedentary, moderately and well-trained athletes. Most studies use cycle ergometry as the principal mode of exercise [3]; however, a $42 \%$ improvement in time to exhaustion and consistent improvements in endurance performance between 2.3 and $6 \%$ have been reported using a simple $30 \mathrm{~s}$ maximal effort shuttle running protocol [47]. The primary mechanisms underpinning these performance changes appear to be peripherally mediated with principle improvements in the content 
and function of oxidative enzymes [48]. Sprint interval training requires large rates of calcium release from the sarcoplasmic reticulum to enable rapid cross-bridge cycling, induces rapid changes in energy status of the muscle cell (ATP $>$ ADP $>$ AMP), requires high rates of glycolysis generating pyruvate production/oxidation and lactate accumulation, providing an increase and accumulation of free-radicals, ions and metabolites [3]. These physiological responses stimulate cell signaling pathways associated with mitochondrial biogenesis, with decreases in muscular Pcr, and glycogen and increases in $[\mathrm{H}+]$ and adrenaline closely linked to early molecular changes in mRNA content of PGC- $1 \alpha$ and additional key regulators of mitochondrial biogenesis [48]. The time course for meaningful adaptations resulting from sprint interval training appears to be in the region of 6 to 9 sessions (3 to 4 weeks) $[44,47]$. Sprint interval training is therefore ideal for combat athletes at the start of camp, in the general preparation phase because of the rapid adaptations in oxidative and mechanical properties associated with success in combat sports.

\subsection{High-Intensity Interval Training}

A key aim of any high-intensity conditioning program is to improve aerobic capacity; high-intensity interval training can be placed in the special preparation phase to induce central cardiovascular adaptations and build upon the peripheral adaptations induced in the general preparatory phase. If required, athletes can cycle between general preparation and special preparatory phases until a competition date has been secured. These sessions can be performed using running, upper and lower body combined ergometry and using bodyweight-style circuit training. Several studies have documented the effectiveness of high-intensity interval training to improve performance and aerobic capacity $[49,50]$ and high-intensity interval training (as defined above) is well established as a key variable in elite endurance athletes training programs [51,52]. The primary goal of interval training is to improve maximum aerobic capacity; as such, the focus of HIIT is to optimize the time close to $\dot{\mathrm{VO}}_{2 \max }$ and at or close to maximum stroke volume. However, assessing oxygen uptake and stroke volume is not an option for many athletes and coaches; and as such, \% of maximum heart rate or heart rate reserve are often used as a proxy for cardiac strain and cardiovascular demand. Key cardiovascular adaptations resulting from HIIT include improved blood volume and red cell mass, capillarization and mitochondrial function and volume, as well as ventricular compliance and cardiac dimensions such as left ventricular hypertrophy [41]. In accordance with these physiological adaptations, endurance performance and improvements in physiological characteristics are typically realized within 4 weeks of HIIT [46]. High-intensity interval training is a well-established and key training strategy for combat athletes because it is effective at improving the key physiological factors that underpin high-intensity performance. Moreover, high-intensity interval training variables can also be manipulated to simulate time-motion characteristics of combat sports whilst imposing a significant cardiovascular demand to develop highintensity performance.

\subsection{Muscle Buffer Training}

High-intensity activity in combat sports is associated with a decrease in cellular $\mathrm{pH}$, primarily induced by an increase in $\left[\mathrm{H}^{+}\right][16]$, caused by activation of anaerobic glycolysis. These demands place limitations on excitation-contraction coupling mechanisms, impairment of cross-bridge cycling and inactivation of key glycolytic enzymes [43]. Such deleterious effects combine to decrease glycolytic activity, even in short sprints, which in combat sports limits tactical options, such as bursts of activity and attempts to finish a contest, which require high-rates of glycolytic flux, (supported by aerobic metabolism) to fuel 8 to $12 \mathrm{~s}$ of high-intensity activity. In an attempt to maintain cellular homeostasis, several buffering mechanisms are activated in response to accumulation of $\left[\mathrm{H}^{+}\right]$, including sodium-hydrogen exchangers, sodium-bicarbonate co-transporters, and blood bicarbonate buffering [7]. Studies that have observed changes in muscle buffer capacity in response to high-intensity conditioning suggest there is an optimal blood lactate response associated 
with these improvements. It appears that intervals lasting approximately 2 min at an intensity that elicits a blood lactate concentration in the region of $8-12 \mathrm{mmol} \cdot \mathrm{L}^{-1}$, repeated 6 to 12 times, 3 times per week for 8 weeks $[53,54]$ are effective at improving high-intensity performance by enhancing muscle buffering capacity.

\subsection{Speed Endurance Training}

High-intensity performance is dependent on a well-adapted neuromuscular system, which at the muscle is largely limited by $\mathrm{Na}^{+}-\mathrm{K}^{+}$pump capability to maintain muscle membrane potential and therefore neuromuscular activation. Nielsen et al. [55] demonstrated an increased $\mathrm{Na}^{+}-\mathrm{K}^{+}$pump $\alpha 1$ - and $\alpha 2$-subunits after 8 weeks of speed endurance training which were also associated with a reduced muscle interstitial $\mathrm{K}^{+}$concentration during exercise. In addition, Iaia et al. [56] observed a $29 \%$ higher expression of muscle $\mathrm{Na}^{+}-\mathrm{K}^{+}$ pump $\alpha 1$-subunits in well-trained participants after a 4 week period of sprint training. This increase in pump content was associated with a reduced plasma $\mathrm{K}^{+}$concentration during exercise, improved performance in a 30 s sprint test, Yo-Yo intermittent recovery test, and two exhaustive runs at $130 \% \dot{\mathrm{VO}}_{2 \max }(7,19,27$, and $19 \%$, respectively). The time course of these adaptions appears to be similar to sprint interval training (6 to 10 sessions), indeed the two types of training in the scientific literature are very similar in terms of apparent intensity and duration, but speed endurance typically entails a greater number of repetitions (up to 10). This suggests that the intensity of speed endurance is less than sprint interval training, differentiated in part by volume and pacing of participants during the session, and by the requirement to produce maximum effort against a resistance in sprint interval training. As combat sports require high-threshold motor unit recruitment in the face of substantial cellular acidosis, training that improves the mechanisms that determine neuromuscular function under these conditions would benefit combat sport athletes.

\section{Integrating Strength Qualities with High-Intensity Conditioning}

The requirement for both well-developed endurance and strength qualities creates complexities when designing training plans for combat sport athletes. It is well documented that in athletes with a high overall training volume (such as combat sport competitors) that the inclusion of endurance training can limit the adaptations to strength training when compared to strength training alone [35]. This appears to be because the high metabolic stress induced by concurrent training leads to an upregulation of p53 causing a decrease in ribosome biogenesis $[57,58]$. Periodization strategies can be employed that pair specific endurance and strength qualities in training phases and subphases in an attempt to manage the training stress. This integration is then sequenced (across time) in a way that the development of one strength quality positively influences the development of the next in sequence. Such a process is often referred to as phase potentiation [59].

It has been suggested that the primary interference of endurance training on the enhancement of strength qualities occurs when peripheral metabolic functions (i.e., capillary density, oxidative enzymatic activity, mitochondria biogenesis) are targeted alongside the development of hypertrophy [60]. As these metabolic adaptations are characteristic of sprint interval training, there is a potential conflict between the development of hypertrophy alongside intense conditioning; however, this potential negative interaction can be alleviated by scheduling conditioning and strength training on separate days with up to $36 \mathrm{~h}$ between sessions (for example, Monday morning early strength training and Tuesday evening conditioning). The inclusion of lower-intensity endurance training in the general preparation subphase will conflict less with peripheral neuromuscular adaptations such muscular endurance and cross-sectional area. These muscle functions also provide a favorable neuromuscular foundation for the development of maximal strength in the later stages of the training plan $[61,62]$. However, it is important to note that although each subphase will emphasize a particular strength quality, maintenance doses targeting alternate strength attributes will still need to be included. Table 3 provides an example of this integration and sequencing process. 
Table 3. Recommendations for the integration of sport-specific training, high-intensity conditioning and resistance training for combat athletes.

\begin{tabular}{|c|c|c|c|c|c|c|}
\hline & Focus & $\begin{array}{c}\text { Weeks 0-4 } \\
\text { General Preparation }\end{array}$ & $\begin{array}{c}\text { Week 5-8 } \\
\text { Specific Preparation }\end{array}$ & $\begin{array}{c}\text { Week 9-12 } \\
\text { Pre-Competition }\end{array}$ & $\begin{array}{l}\text { Week 13-16 } \\
\text { Competition }\end{array}$ & Transition \\
\hline \multirow{3}{*}{ Conditioning } & Primary & $\begin{array}{l}\text { Sports specific drilling } \\
\text { (RPE 3-5) } \\
\text { Sprint interval training } \\
\text { (RPE 10) } \\
\end{array}$ & $\begin{array}{l}\text { Sports specific drilling } \\
\text { (RPE 5-7) } \\
\text { Short HIIT } \\
\text { (RPE 8-9) } \\
\end{array}$ & $\begin{array}{c}\text { Sports specific sparring } \\
\text { (RPE 5-7) } \\
\text { Muscle buffer training (RPE } \\
7-8 \text { ) } \\
\end{array}$ & $\begin{array}{l}\text { Sports specific sparring } \\
\text { (RPE 7-9) } \\
\text { Speed endurance } \\
\text { (RPE 7-8) }\end{array}$ & $\begin{array}{l}\text { Dependent on individual factors: } \\
\text { post-bout injury and fatigue status. } \\
\text { Objective is to allow rejuvenation, but } \\
\text { minimise decay of physical qualities. }\end{array}$ \\
\hline & Secondary & $\begin{array}{l}\text { Recovery and endurance } \\
\text { focussed conditioning } \\
\text { (RPE 1-3) }\end{array}$ & $\begin{array}{l}\text { Sports specific sparring } \\
\text { (RPE 3-5) } \\
\text { Long HIIT } \\
\text { (RPE 8-9) }\end{array}$ & $\begin{array}{l}\text { Sports specific drilling } \\
\text { (RPE 3-5) } \\
\text { Recovery based } \\
\text { conditioning } \\
\text { (RPE 1-3) }\end{array}$ & $\begin{array}{l}\text { Sports specific drilling } \\
\text { (RPE 5-7) }\end{array}$ & \\
\hline & Tertiary & $\begin{array}{l}\text { Sports specific sparring } \\
\text { (RPE 3-5) }\end{array}$ & $\begin{array}{l}\text { Recovery based } \\
\text { conditioning } \\
\text { (RPE 1-3) }\end{array}$ & $\begin{array}{l}\text { Speed endurance } \\
\text { (RPE 3-5) }\end{array}$ & $\begin{array}{c}\text { Short HIIT/specific } \\
\text { time-motion patterns } \\
\text { Speed and high-rate of force } \\
\text { development } \\
\text { (RPE 3-5) }\end{array}$ & \\
\hline \multirow{3}{*}{ Resistance Training } & Primary & $\begin{array}{l}\text { Hypertrophy, strength } \\
\text { endurance, muscle balance }\end{array}$ & Basic strength & Basic strength & $\begin{array}{l}\text { Maximal strength and rate } \\
\text { of force development (high } \\
\text { velocity emphasis) }\end{array}$ & \\
\hline & Secondary & Basic strength & $\begin{array}{l}\text { Hypertrophy, strength } \\
\text { endurance, muscle balance }\end{array}$ & $\begin{array}{l}\text { Rate of force development } \\
\text { (high force emphasis) }\end{array}$ & Basic strength & \\
\hline & Tertiary & $\begin{array}{l}\text { Rate of force development } \\
\text { (technique development) }\end{array}$ & $\begin{array}{l}\text { Rate of force development } \\
\text { (technique development) }\end{array}$ & Strength endurance & Strength endurance & \\
\hline
\end{tabular}




\section{Conclusions}

The aim of this article was to (i) summarize the physiological demands of combat sports; (ii) present the primary considerations required to program high-intensity conditioning for athletes; (iii) define and present key high-intensity conditioning methods; and (iv) provide guidance for scientists and coaches to help prepare athletes under common but differing circumstances.

Combat sports are characterized as high-intensity intermittent sports and therefore require training strategies that support the high-intensity nature of these sports. Most combat sports, particularly more so in 'professional' versions of combat sports such as boxing, have typical considerations such as the irregular scheduling of bouts, making weight and the athletes training history. Identifying and understanding these considerations should be a key focus for coaches as these factors influence the duration and therefore the type of high-intensity training that can be used at any stage in the training process. In addition to the empirical evidence demonstrating the applicability of high-intensity conditioning with combat athletes in this manuscript, review articles focusing on high-intensity conditioning for combat sports $[9,10]$ have recommended that future research should be conducted to evaluate the effectiveness of HIT on specific physical capabilities and combine this with sport-specific performance tests. Indeed, at the time of writing, only one study has investigated the effect of high-intensity conditioning on physiology and performance of MMA athletes. Kostikiadis et al. [63] used circuit training, and therefore, a hybrid training approach (i.e., did not isolate physiological targets or adaptations) and demonstrated statistically significant improvements in a range of physical tests compared to a control group after 4 weeks of training. We therefore encourage practitioners and scientists to use the present manuscript as a basis from which to implement high-intensity conditioning in training and research.

Author Contributions: Conceptualization, A.R., L.J. and D.F.; writing-original draft preparation, A.R., L.J. and D.F.; writing-review and editing, A.R., L.J., D.F., D.R., M.D. and D.H. All authors have read and agreed to the published version of the manuscript.

Funding: This research received no external funding.

Institutional Review Board Statement: Not applicable.

Informed Consent Statement: Not applicable.

Data Availability Statement: Not applicable.

Conflicts of Interest: The authors declare no conflict of interest.

\section{References}

1. James, L.P.; Haff, G.G.; Kelly, V.; Beckman, E. Towards a determination of the physiological characteristics distinguishing successful mixed martial arts athletes: A systematic review of combat sport literature. Sports Med. 2016, 46, 1525-1551. [CrossRef]

2. Ruddock, A.D.; Wilson, D.C.; Thompson, S.W.; Hembrough, D.; Winter, E.M. Strength and conditioning for professional boxing. Strength Cond. J. 2016, 38, 81-90. [CrossRef]

3. MacInnis, M.J.; Gibala, M.J. Physiological adaptations to interval training and the role of exercise intensity. J. Physiol. 2017, 595, 2915-2930. [CrossRef] [PubMed]

4. Bangsbo, J. Performance in sports-with specific emphasis on the effect of intensified training. Scand. J. Med. Sci. Sports 2015, 25, 88-99. [CrossRef] [PubMed]

5. Buchheit, M.; Laursen, P.B. High-intensity interval training, solutions to the programming puzzle: Part I: Cardiopulmonary emphasis. Sports Med. 2013, 43, 313-338. [CrossRef]

6. Buchheit, M.; Laursen, P.B. High-intensity interval training, solutions to the programming puzzle: Part II: Anaerobic energy, neuromuscular load and practical applications. Sports Med. 2013, 43, 927-954. [CrossRef]

7. Girard, O.; Mendez-Villanueva, A.; Bishop, D. Repeated-sprint ability-Part I. Sports Med. 2011, 41, 673-694. [CrossRef] [PubMed]

8. Bishop, D.; Girard, O.; Mendez-Villanueva, A. Repeated-sprint ability-Part II. Sports Med. 2011, 41, 741-756. [CrossRef]

9. Franchini, E. High-intensity interval training prescription for combat-sport athletes. Int. J. Sports Physiol. Perform. 2020, 15, 767-776. [CrossRef] [PubMed]

10. Vasconcelos, B.B.; Protzen, G.V.; Galliano, L.M.; Kirk, C.; Del Vecchio, F.B. Effects of high-intensity interval training in combat sports: A systematic review with meta-analysis. J. Strength Cond. Res. 2020, 34, 888-900. [CrossRef] 
11. Chaabène, H.; Hachana, Y.; Franchini, E.; Mkaouer, B.; Montassar, M.; Chamari, K. Reliability and construct validity of the karate-specific aerobic test. J. Strength Cond. Res. 2012, 26, 3454-3460. [CrossRef]

12. Del Vecchio, F.B.; Hirata, S.M.; Franchini, E. A review of time-motion analysis and combat development in mixed martial arts matches at regional level tournaments. Percept. Mot. Ski. 2011, 112, 639-648. [CrossRef] [PubMed]

13. Miarka, B.; Brito, C.J.; Moreira, D.G.; Amtmann, J. Differences by ending rounds and other rounds in time-motion analysis of mixed martial arts: Implications for assessment and training. J. Strength Cond. Res. 2018, 32, 534-544. [CrossRef] [PubMed]

14. Miarka, B.; Coswig, V.S.; Amtmann, J. Long MMA fights technical-tactical analysis of mixed martial arts: Implications for assessment and training. Int. J. Perform. Anal. Sport 2019, 19, 153-166. [CrossRef]

15. Kirk, C.; Hurst, H.T.; Atkins, S. Measuring the workload of mixed martial arts using accelerometry, time motion analysis and lactate. Int. J. Perform. Anal. Sport 2015, 15, 359-370. [CrossRef]

16. Hanon, C.; Savarino, J.; Thomas, C. Blood lactate and acid-base balance of world-class amateur boxers after three 3-minute rounds in international competition. J. Strength Cond. Res. 2015, 29, 942-946. [CrossRef] [PubMed]

17. Gaitanos, G.C.; Williams, C.; Boobis, L.H.; Brooks, S. Human muscle metabolism during intermittent maximal exercise. J. Appl. Physiol. 1993, 75, 712-719. [CrossRef] [PubMed]

18. Parolin, M.L.; Spriet, L.L.; Hultman, E.; Hollidge-Horvat, M.G.; Jones, N.L.; Heigenhauser, G.J.F. Regulation of glycogen phosphorylase and PDH during exercise in human skeletal muscle during hypoxia. Am. J. Physiol. Metab. 2000, 278, E522-E534. [CrossRef]

19. Smith, M.S. Physiological profile of senior and junior England international amateur boxers. J. Sports Sci. Med. 2006, 5, 74-89. [PubMed]

20. Slimani, M.; Chaabene, H.; Miarka, B.; Franchini, E.; Chamari, K.; Cheour, F. Kickboxing review: Anthropometric, psychophysiological and activity profiles and injury epidemiology. Biol. Sport 2017, 34, 185-196. [CrossRef]

21. Franchini, E.; Artioli, G.G.; Brito, C.J. Judo combat: Time-motion analysis and physiology. Int. J. Perform. Anal. Sport 2013, 13, 624-641. [CrossRef]

22. Chaabene, H.; Negra, Y.; Bouguezzi, R.; Mkaouer, B.; Franchini, E.; Julio, U.; Hachana, Y. Physical and physiological attributes of wrestlers: An update. J. Strength Cond. Res. 2017, 31, 1411-1442. [CrossRef] [PubMed]

23. Bridge, C.A.; da Silva Santos, J.F.; Chaabene, H.; Pieter, W.; Franchini, E. Physical and physiological profiles of taekwondo athletes. Sports Med. 2014, 44, 713-733. [CrossRef] [PubMed]

24. Jones, A.M.; Vanhatalo, A. The 'Critical Power' concept: Applications to sports performance with a focus on intermittent high-intensity exercise. Sports Med. 2017, 47, 65-78. [CrossRef]

25. Chidnok, W.; Dimenna, F.J.; Bailey, S.; Vanhatalo, A.; Morton, R.H.; Wilkerson, D.P.; Jones, A.M. Exercise tolerance in intermittent cycling. Med. Sci. Sports Exerc. 2012, 44, 966-976. [CrossRef]

26. Billat, V.; Binsse, V.; Petit, B.; Koralsztein, J.J. High level runners are able to maintain a VO2 steady-state below VO2max in an all-out run over their critical velocity. Arch. Physiol. Biochem. 1998, 106, 38-45. [CrossRef]

27. Bell, L.; Ruddock, A.; Maden-Wilkinson, T.; Rogerson, D. Overreaching and overtraining in strength sports and resistance training: A scoping review. J. Sports Sci. 2020, 38, 1897-1912. [CrossRef]

28. Bell, L.; Ruddock, A.; Maden-Wilkinson, T.; Hembrough, D.; Rogerson, D. "Is it overtraining or just work ethic?": Coaches' perceptions of overtraining in high-performance strength sports. Sports 2021, 9, 85. [CrossRef]

29. Reale, R.J.; Slater, G.; Burke, L.M. Individualised dietary strategies for Olympic combat sports: Acute weight loss, recovery and competition nutrition. Eur. J. Sport Sci. 2017, 17, 727-740. [CrossRef]

30. Franchini, E.; Brito, C.J.; Artioli, G.G. Weight loss in combat sports: Physiological, psychological and performance effects. J. Int. Soc. Sports Nutr. 2012, 9, 52. [CrossRef]

31. Reale, R.; Dunican, I.; Slater, G.; Burke, L.M. Water loading in combat sport athletes as a means to acutely manipulate body mass. Med. Sci. Sports Exerc. 2017, 49, 680. [CrossRef]

32. Reale, R.; Slater, G.; Burke, L.M. Acute-weight-loss strategies for combat sports and applications to Olympic success. Int. J. Sports Physiol. Perform. 2017, 12, 142-151. [CrossRef] [PubMed]

33. Bromley, S.J.; Drew, M.K.; Talpey, S.; McIntosh, A.S.; Finch, C.F. A systematic review of prospective epidemiological research into injury and illness in Olympic combat sport. Br. J. Sports Med. 2018, 52, 8-16. [CrossRef] [PubMed]

34. Plisk, S.S.; Stone, M.H. Periodization Strategies. Strength Cond. J. 2003, 25, 19-37. [CrossRef]

35. Wilson, J.M.; Marin, P.J.; Rhea, M.R.; Wilson, S.M.; Loenneke, J.P.; Anderson, J.C. Concurrent training. J. Strength Cond. Res. 2012, 26, 2293-2307. [CrossRef] [PubMed]

36. Foster, C.; Florhaug, J.A.; Franklin, J.; Gottschall, L.; Hrovatin, L.A.; Parker, S.; Doleshal, P.; Dodge, C. A new approach to monitoring exercise training. J. Strength Cond. Res. 2001, 15, 109-115. [PubMed]

37. Bosquet, L.; Montpetit, J.; Arvisais, D.; Mujika, I. Effects of tapering on performance. Med. Sci. Sports Exerc. 2007, 39, 1358-1365. [CrossRef]

38. Haugen, T.; Paulsen, G.; Seiler, S.; Sandbakk, Ø. New records in human power. Int. J. Sports Physiol. Perform. 2018, 13, 678-686. [CrossRef]

39. Robinson, S.; Edwards, H.T.; Dill, D.B. New records in human power. Science 1937, 85, 409-410. [CrossRef]

40. Åstrand, P.-O. New Records in Human Power. Nat. Cell Biol. 1955, 176, 922-923. [CrossRef] 
41. Lundby, C.; Montero, D.; Joyner, M. Biology of VO2max: Looking under the physiology lamp. Acta Physiol. 2016, 220, 218-228. [CrossRef] [PubMed]

42. Jacobs, R.A.; Lundby, C. Mitochondria express enhanced quality as well as quantity in association with aerobic fitness across recreationally active individuals up to elite athletes. J. Appl. Physiol. 2013, 114, 344-350. [CrossRef] [PubMed]

43. Hostrup, M.; Bangsbo, J. Limitations in intense exercise performance of athletes-effect of speed endurance training on ion handling and fatigue development. J. Physiol. 2017, 595, 2897-2913. [CrossRef] [PubMed]

44. Burgomaster, K.A.; Howarth, K.R.; Phillips, S.; Rakobowchuck, M.; MacDonald, M.; McGee, S.; Gibala, M.J. Similar metabolic adaptations during exercise after low volume sprint interval and traditional endurance training in humans. J. Physiol. 2008, 586, 151-160. [CrossRef]

45. Iaia, F.M.; Bangsbo, J. Speed endurance training is a powerful stimulus for physiological adaptations and performance improvements of athletes. Scand. J. Med. Sci. Sports 2010, 20, 11-23. [CrossRef]

46. Sylta, Ø.; Tønnessen, E.; Sandbakk, Ø.; Hammarström, D.; Danielsen, J.; Skovereng, K.; Rønnestad, B.R.; Seiler, S. Effects of high-intensity training on physiological and hormonal adaptions in well-trained cyclists. Med. Sci. Sports Exerc. 2017, 49, 1137-1146. [CrossRef]

47. Koral, J.; Oranchuk, D.J.; Herrera, R.; Millet, G.Y. Six sessions of sprint interval training improves running performance in trained athletes. J. Strength Cond. Res. 2018, 32, 617-623. [CrossRef]

48. Fiorenza, M.; Gunnarsson, T.P.; Hostrup, M.; Iaia, F.M.; Schena, F.; Pilegaard, H.; Bangsbo, J. Metabolic stress-dependent regulation of the mitochondrial biogenic molecular response to high-intensity exercise in human skeletal muscle. J. Physiol. 2018, 596, 2823-2840. [CrossRef]

49. Bacon, A.P.; Carter, R.E.; Ogle, E.A.; Joyner, M.J. VO2max trainability and high intensity interval training in humans: A meta-analysis. PLoS ONE 2013, 8, e73182. [CrossRef]

50. Weston, M.; Taylor, K.L.; Batterham, A.M.; Hopkins, W.G. Effects of low-volume high-intensity interval training (HIT) on fitness in adults: A meta-analysis of controlled and non-controlled trials. Sports Med. 2014, 44, 1005-1017. [CrossRef]

51. Tønnessen, E.; Sylta, Ø.; Haugen, T.A.; Hem, E.; Svendsen, I.S.; Seiler, S. The road to gold: Training and peaking characteristics in the year prior to a gold medal endurance performance. PLoS ONE 2014, 9, e101796. [CrossRef]

52. Stöggl, T.L.; Sperlich, B. The training intensity distribution among well-trained and elite endurance athletes. Front. Physiol. 2015 6, 295. [CrossRef] [PubMed]

53. Edge, J.; Hill-Haas, S.; Goodman, C.; Bishop, D. Effects of resistance training on H+ regulation, buffer capacity, and repeated sprints. Med. Sci. Sports Exerc. 2006, 38, 2004-2011. [CrossRef] [PubMed]

54. Edge, J.; Bishop, D.; Goodman, C. The effects of training intensity on muscle buffer capacity in females. Graefe's Arch. Clin. Exp. Ophthalmol. 2006, 96, 97-105. [CrossRef]

55. Nielsen, J.J.; Mohr, M.; Klarskov, C.; Kristensen, M.; Krustrup, P.; Juel, C.; Bangsbo, J. Effects of high-intensity intermittent training on potassium kinetics and performance in human skeletal muscle. J. Physiol. 2004, 554, 857-870. [CrossRef]

56. Iaia, F.M.; Thomassen, M.; Kolding, H.; Gunnarsson, T.P.; Wendell, J.; Rostgaard, T.; Nordsborg, N.; Krustrup, P.; Nybo, L.; Hellsten, Y.; et al. Reduced volume but increased training intensity elevates muscle Na+-K+ pump $\alpha 1$-subunit and NHE1 expression as well as short-term work capacity in humans. Am. J. Physiol. Integr. Comp. Physiol. 2008, 294, R966-R974. [CrossRef] [PubMed]

57. Bartlett, J.D.; Joo, C.H.; Jeong, T.-S.; Louhelainen, J.; Cochran, A.J.; Gibala, M.J.; Gregson, W.; Close, G.; Drust, B.; Morton, J.P. Matched work high-intensity interval and continuous running induce similar increases in PGC-1 $\alpha$ mRNA, AMPK, p38, and p53 phosphorylation in human skeletal muscle. J. Appl. Physiol. 2012, 112, 1135-1143. [CrossRef] [PubMed]

58. Bartlett, J.D.; Louhelainen, J.; Iqbal, Z.; Cochran, A.J.; Gibala, M.J.; Gregson, W.; Close, G.; Drust, B.; Morton, J.P. Reduced carbohydrate availability enhances exercise-induced p53 signaling in human skeletal muscle: Implications for mitochondrial biogenesis. Am. J. Physiol. Integr. Comp. Physiol. 2013, 304, R450-R458. [CrossRef] [PubMed]

59. Stone, M.H.; Sanborn, K.I.M.; O’Bryant, H.S.; Hartman, M.; Stone, M.E.; Proulx, C.; Ward, B.; Hruby, J. Maximum strength-powerperformance relationships in collegiate throwers. J. Strength Cond. Res. 2003, 17, 739-745. [CrossRef]

60. Pallares, J.G.; Izquierdo, M. Strategies to optimize concurrent training of strength and aerobic fitness for rowing and canoeing. Sports Med. 2011, 41, 329-343. [CrossRef]

61. James, L.P.; Haff, G.G.; Kelly, V.; Connick, M.J.; Hoffman, B.W.; Beckman, E.M. The impact of strength level on adaptations to combined weightlifting, plyometric, and ballistic training. Scand. J. Med. Sci. Sports 2017, 28, 1494-1505. [CrossRef] [PubMed]

62. Zamparo, P.; Minetti, A.; Di Prampero, P. Interplay among the changes of muscle strength, cross-sectional area and maximal explosive power: Theory and facts. Graefe's Arch. Clin. Exp. Ophthalmol. 2002, 88, 193-202. [CrossRef]

63. Kostikiadis, I.N.; Methenitis, S.; Tsoukos, A.; Veligekas, P.; Terzis, G.; Bogdanis, G.C. The effect of short-term sport-specific strength and conditioning training on physical fitness of well-trained mixed martial arts athletes. J. Sports Sci. Med. 2018, 17, 348-358. [PubMed] 